\title{
REVIEW
}

\section{Regional Dialect Diversity and Corporate Strategic Aggressiveness}

\section{Bingyuan Xie*}

School of Accountancy, Central University of Finance and Economics, Beijing, 100081, China

\begin{tabular}{l}
\hline ARTICLE INFO \\
\hline Article history \\
Received: 28 March 2020 \\
Revised: 7 April 2020 \\
Accepted: 9 April 2020 \\
Published Online: 16 April 2020 \\
\hline
\end{tabular}

Keywords:

Culture and corporate behavior

Dialect diversity

Degree of strategic aggressiveness

\section{Introduction}

hina is a multi-ethnic country, where multiculturalism coexists, and one of the manifestations is that Mandarin and dialect are parallel. In 1982, China wrote "the state promotes the use of Mandarin throughout the country" into the Constitution, but people still use dialects extensively in daily lives. Dialects have both instrumental and cultural attributes, on the one hand, is a vehicle for people's expression and communication and a carrier of information in economic activities; on the other hand, dialect is an important representative of regional culture and an important dimension of ethnic di-

\begin{abstract}
As an important role of the regional culture, dialects have a significant influence on the corporate strategy. Diversity of dialects appears to move firms towards strategic radicalization by weakening the "hometown effect", enhancing innovation awareness, and increasing the diversification of business. Using A-share listed companies from 2006 to 2018 as sample, based on information from the annual financial statements, this paper argues that higher dialect diversity in the city where enterprise is located leads the corporate strategy to be more aggressive; and the mismatch between strategy and dialectal environment will have a negative effect on corporate performance. After a series of robustness tests and using instrumental variables to solve endogenous problems, the conclusions remain consistent. Further study indicates that the influence of dialect diversity on strategy is enhanced as managers' awareness of the dialectal environment increases, but is weaken if the enterprise is a state-owned enterprise or has larger scale. This research reveals the connection between dialect culture and corporate behavior form a strategic level, provides empirical evidence and enriches the literature for the traditional view of "culture influences strategy", and has significance on promoting the corporate strategic management practices.
\end{abstract}

vision and identification. The dual roles of dialects have a profound impact on socio-economic life.

There is no unified conclusion on the impact of dialect diversity on corporate behavior in the existing literature and most of which only focused on the impact at a specific aspect, and ignored the influence of dialect on the corporate strategy at the overall level. In practice, strategy determines the corporate business goals, development direction, and action plan (Porter, 1980), laying the cornerstone of the corporate long-term development. The enterprise cannot change the external environment, and its strategy must adapt to the status and trends of the external environment---The process of strategic selection is essentially a process of

*Corresponding Author:

Bingyuan Xie;

School of Accountancy, Central University of Finance and Economics, No. 39 Xueyuan South Road, Haidian District, Beijing, 100081, China;

Email: xiebingyuan_a@163.com 
matching the internal characteristics of the enterprise with the external environment. In general, enterprises inevitably have problems of language communication in both internal and external communication, human resource management and trade negotiation. Moreover, local dialects are important tools for the enterprise to communicate internally and externally, which in turn affects the business development and strategic decisions of the enterprise. So, our research into the relationship between dialect and strategy would be interesting and necessary.

Based on this, the paper focuses on how dialect diversity becomes a key factor that cannot be ignored in the setting of corporate strategy, and further explores how this factor has a subtle influence on the enterprise's overall strategic setting as an external cultural environment.

\section{Theoretical Analysis and Research Hypoth- eses}

The management literature on corporate strategy typology is quite abundant, in which according to the degree of radicalization and according to the definition of Miles and Snow (2003), the corporate strategy is divided into prospector, analyzer and defender. Companies that implement different strategies have significant differences in their business models and organizational structures. The prospectors are keen on product creation, technology R\&D, and market expansion. Therefore, they generally need to establish multiple branches or subsidiaries, which makes their organizational structure more fragmented and complicated. But a defender usually focuses on several existing products or services, with a more centralized organizational structure and a more stable management team. Bentley et al. (2013) used financial statement information to describe the above typology and received a wide range of recognition. Subsequently, a group of domestic and foreign scholars conducted researches on the relationship between corporate strategy and corporate financial behavior with reference to the measurement methods of Bentley et al. (2013) (Higgins et al., 2015; Habib, 2017).

But at the empirical level, the literature does not pay much attention to the impact of external environment on corporate strategic decisions, and to some extent ignores the existence of cultural factors, which gives room for this paper. The paper presents that the regional dialect diversity may affect corporate strategy via the following ways:

Firstly, dialect diversity can increase an enterprise's innovation awareness and risk appetite. The cultural diversity implied by linguistic diversity can bring about the collision and inspiration of different ideas, giving companies a stronger incentive to innovate. Therefore, in regions with more diverse dialects, companies may lay out more innovation activities. On the contrast, in areas where dialects are concentrated, companies will be subject to more non-institutional constraints when making strategic decisions, moreover, the cultural dependency formed by the connection of "township" also makes the enterprise tend to maintain stable operation due to the influence of "hometown preference" and "path dependence" when it expands abroad. The more informal external constraints the enterprise faces, the more it tends to be conservative.

Secondly, dialect diversity prompts the enterprise's business scope to passively expand. Lower dialect diversity leads to higher possibility of two groups speaking one dialect, so long-term relationships with business partners are more likely to develop in a region. Language has both cultural identity recognition and interpersonal communication functions, so it plays an important role in promoting business negotiations and sales contracting, and reduce transaction costs. Then the enterprise may be unwilling to waste such "dialectic advantages", tending to conduct business in a certain dialect area, and not having enough motivation for product or service innovation, making the corporate strategy more conservative. As companies in complex dialects have lost such advantages, in order to maintain competitiveness, they are more likely to expand their business out of local market, and then formulate a broader business expansion strategy, and diversify their business as much as possible to reduce their own risks.

Thirdly, dialect diversity weakens "hometown effect" and makes the organizational structure of enterprises more fluid. The natural psychological distance brought by dialect diversity will lead to the phenomenon of group exclusion. With the weakening of language identity, the phenomenon of "township clique" brought about by the distance of language can be gradually eliminated, and the personnel turnover of the enterprise will be more frequent.

Based on the above discussion, in areas where the dialects are more diversified, the managers will adjust the corporate strategy through specific paths such as increasing investment in R\&D innovation and market expansion, increasing the degree of business diversification, decentralizing the allocation of assets, and enhancing the mobility of internal personnel. Based on this, this paper proposes the core hypothesis:

Hypothesis 1: Corporate strategy will be more aggressive when located in areas with higher dialect diversity.

\section{Methodology}

\subsection{Data Source and Processing}

This paper takes the Chinese A-share listed companies 
from 2006 to 2018 as the research sample, and the required financial data comes from the CSMAR database. Dialect diversity data comes from a dialect database constructed by Xu Xianxiang et al. (2015).Drawing on the existing research, this paper processed the sample as follows: (1) remove the companies in financial industries; (2) since five years of financial data is needed, companies that have been listed for less than five years is excluded; (3) drop samples with missing data; (4) Tails the continuous variables at the levels of $1 \%$ and $99 \%$. After the above screening, this paper finally obtained 16024 "enterprise-year" samples.

\subsection{Model Design and Variable Definition}

This paper builds a Test Model (1) of Hypothesis 1 as follows:

$$
\begin{gathered}
\text { Strategy }_{i},=\beta_{0}+\beta_{1} * \text { Dialect Diversity }+ \text { Control }_{i},+ \text { Indus- }^{-} \\
\text {try }+ \text { Year }+\varepsilon_{i}
\end{gathered}
$$

\subsubsection{Explained Variables}

The discrete variable Strategy serves as the explanatory variable and represents the corporate strategy. Drawing on existing literature (Bentley et al., 2013), this paper measures it from the following six dimensions: (1) The ratio of $R \& D$ expenses to operating income, reflecting the enterprise's tendency of innovation; (2) The ratio of selling and administrative expense to operating income, reflecting the market expansion tendency; (3) The growth rate of operating income, reflecting the growth of the enterprise; (4) The ratio of staff number to operating income, reflecting the enterprise's production efficiency; (5) The standard deviation of the number of employees, reflecting the stability of the organizational structure; (6) The ratio of fixed assets to total assets, reflecting the capital density. For the above six indicators, this paper first calculates the average of the past five years, and then sorts the indicators by "Industry-Year" from small to large and assigns a score of 1-5. Finally, the scores of the six dimensions are added to obtain a score ranging from 6 to 30 points, which is called strategic aggressiveness. Higher score represents a more aggressive strategy.

\subsubsection{Explanatory Variables}

DiaDiv and DiaNum are the variables for dialect diversity and the main explanatory variables, quoted from $\mathrm{Xu}$ Xianxiang et al. (2015) dialect database, which uses prefecture-level administrative divisions as analysis units to measure the diversity of dialects within a city. One is the Dialect Diversity Index (DiaDiv), which is a weight- ed average based on the proportion of the population of a dialect in a city; The second is the number of Chinese sub-dialects used in the city (DiaNum).

\subsubsection{Controlled Variables}

We include controls for the main characteristics of the enterprise, the board of directors and management, the market environment and the level of economic development in the region. The specific settings are shown in Table 1.

\begin{tabular}{|c|c|}
\hline Variable symbols & Variable definitions \\
\hline Strategy & $\begin{array}{l}\text { Scoring of six dimensions. 6-12points: Defender. } 13- \\
23 \text { points: Analyzer. } 24-30 \text { points: Prospector }\end{array}$ \\
\hline DiaDiv & $\begin{array}{l}\text { Economically indicates the probability of any two } \\
\text { people randomly selected in the city speaking differ- } \\
\text { ent dialects }\end{array}$ \\
\hline DiaNum & The number of Chinese sub-dialects used in a city \\
\hline Soe & $\begin{array}{l}\text { Indicator variable, coded one if the enterprise is } \\
\text { state-owned and zero otherwise }\end{array}$ \\
\hline Size & Natural logarithm of total assets of the enterprise \\
\hline Lev & Ratio of total liabilities to total assets \\
\hline Roe & Ratio of net profit to net assets \\
\hline FimAge & Years of listing \\
\hline Top5Hold & Shareholding ratio of top five shareholders \\
\hline Board & Number of directors \\
\hline Indep & $\begin{array}{c}\text { Proportion of independent directors in total board } \\
\text { members }\end{array}$ \\
\hline MgAge & $\begin{array}{l}\text { Average age of non-independent directors and execu- } \\
\text { tives }\end{array}$ \\
\hline Market & $\begin{array}{c}\text { Take } 1 \text { if the registered place of enterprise is in the } \\
\text { west China, } 2 \text { in the northeast China, } 3 \text { in the middle } \\
\text { China and } 4 \text { in the East China }\end{array}$ \\
\hline IndPos & $\begin{array}{c}\text { The proportion of the enterprise's operating revenue } \\
\text { in the whole industry }\end{array}$ \\
\hline
\end{tabular}

Table 1. Definition of main empirical variables

\subsubsection{Descriptive Statistics of Variables}

Table 2 reports descriptive statistics, in which the two indicators of dialect diversity report the sample and the overall national statistics. The average and median of the strategy variable are both near 18.00 , which meets the definition of indicator construction; the standard deviation is 4.348 , which indicates sufficient variability. The average of DiaDiv is 0.222 , and the average of DiaNum in prefecture-level cities is 1.722 , indicating that language differentiation indeed exists in the overall environment of the enterprise. In addition, the dialect diversity of the sample is basically consistent with the national distribution, indicating that the sample selection errors can be basically eliminated. 
Table 2. Summary statistics

\begin{tabular}{|c|c|c|c|c|c|}
\hline VarName & Mean & SD & Min & Median & Max \\
\hline Score & 17.888 & 4.348 & 6.000 & 18.000 & 30.000 \\
\hline DiaDiv & 0.222 & 0.195 & 0.001 & 0.220 & 0.782 \\
\hline DiaNum & 1.722 & 0.710 & 1.000 & 2.000 & 4.000 \\
\hline $\begin{array}{c}\text { DiaDiv(Na- } \\
\text { tionwide) }\end{array}$ & 0.314 & 0.243 & 0.000 & 0.321 & 0.7822 \\
\hline $\begin{array}{c}\text { DiaNum (Na- } \\
\text { tionwide) }\end{array}$ & 1.743 & 0.804 & 1.000 & 2.000 & 5.000 \\
\hline Soe & 0.349 & 0.477 & 0.000 & 0.000 & 1.000 \\
\hline Size & 22.088 & 1.268 & 19.746 & 21.904 & 26.048 \\
\hline Lev & 0.430 & 0.207 & 0.049 & 0.424 & 0.916 \\
\hline Roe & 0.066 & 0.123 & -0.603 & 0.069 & 0.362 \\
\hline FimAge & 10.675 & 6.452 & 1.000 & 9.000 & 29.000 \\
\hline Top5hold & 52.507 & 15.117 & 19.173 & 52.530 & 87.661 \\
\hline Board & 8.742 & 1.743 & 0.000 & 9.000 & 18.000 \\
\hline Indep & 0.373 & 0.056 & 0.000 & 0.333 & 0.800 \\
\hline MgAge & 47.685 & 3.732 & 34.700 & 47.862 & 61.000 \\
\hline Market & 3.319 & 1.078 & 1.000 & 4.000 & 4.000 \\
\hline Indpos & 0.029 & 0.066 & 0.000 & 0.006 & 0.424 \\
\hline
\end{tabular}

The impact of dialect diversity on the corporate strategy is shown in Figure 1. The horizontal axis is the number of Chinese sub-dialects, and the vertical axis is the average of all companies' strategic aggressiveness. It can be seen that as the variety of dialects increase, the corporate strategy aggressiveness shows an upward trend. The results in Figure 1 initially confirm that the dialect diversity promotes the corporate strategy to be more radical, in line with the Hypothesis 1.

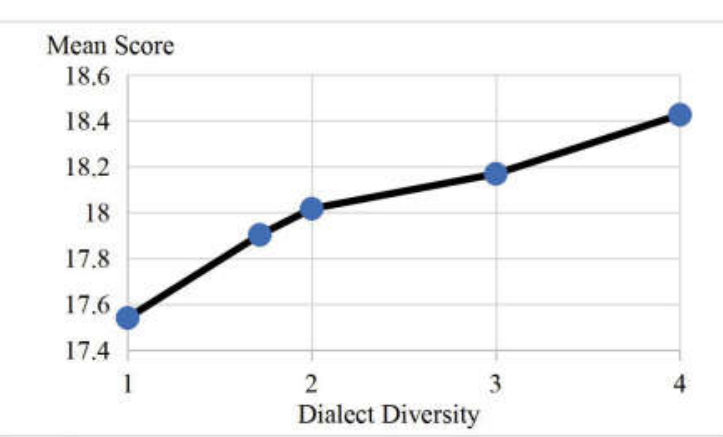

Figure 1. Strategic average score under the diversity of different dialects

\section{Empirical Results}

\subsection{Baseline Tests}

Table 3 presents the multivariate results from Test Model (1). The results reveal a significantly positive association between dialect diversity and corporate strategic aggressiveness. One unit increase of the degree of dialect differentiation will lead to an increase of 1.7 units in corporate strategy radicalization, and each increase in the number of regional sub-dialects will increase the degree of corporate strategy radicalization by 0.5 units. Both coefficients meet the significance requirements at a level of $1 \%$, showing that the diversity and complexity of dialects will indeed prompt companies to formulate more aggressive strategies, supporting the Hypothesis of this paper. In addition, the coefficient of Soe is negative, indicating that the strategy of state-owned enterprises is more conservative than that of non-state-owned enterprises, which is consistent with previous literature conclusions; the coefficient of Roe and the size of the enterprise is also significantly positive, which indicates that companies with better performance and larger sizes are more pioneering in decision-making.

Table 3. Dialect diversity and corporate strategy

\begin{tabular}{|c|c|c|}
\hline & $\begin{array}{c}\text { (1) } \\
\text { Score }\end{array}$ & $\begin{array}{c}\text { (2) } \\
\text { Score }\end{array}$ \\
\hline \multirow[t]{2}{*}{ DiaDiv } & $1.708 * * *$ & \\
\hline & $(3.81)$ & \\
\hline \multirow[t]{2}{*}{ DiaNum } & & $0.508 * * *$ \\
\hline & & $(4.30)$ \\
\hline \multirow[t]{2}{*}{ Soe } & $-0.918 * * *$ & $-0.971 * * *$ \\
\hline & $(-4.49)$ & $(-4.74)$ \\
\hline \multirow[t]{2}{*}{ Size } & $-0.176^{*}$ & $-0.188 * *$ \\
\hline & $(-1.93)$ & $(-2.06)$ \\
\hline \multirow[t]{2}{*}{ Lev } & $-2.523 * * *$ & $-2.478 * * *$ \\
\hline & $(-5.70)$ & $(-5.62)$ \\
\hline \multirow[t]{2}{*}{ Roe } & $2.892 * * *$ & $2.897 * * *$ \\
\hline & $(6.60)$ & $(6.61)$ \\
\hline \multirow[t]{2}{*}{ FimAge } & $-0.071 * * *$ & $-0.070 * * *$ \\
\hline & $(-4.20)$ & $(-4.11)$ \\
\hline \multirow[t]{2}{*}{ Top5hold } & -0.002 & -0.003 \\
\hline & $(-0.37)$ & $(-0.52)$ \\
\hline \multirow[t]{2}{*}{ Board } & -0.081 & -0.084 \\
\hline & $(-1.58)$ & $(-1.62)$ \\
\hline \multirow[t]{2}{*}{ Indep } & -0.415 & -0.298 \\
\hline & $(-0.33)$ & $(-0.24)$ \\
\hline \multirow[t]{2}{*}{ MgAge } & $-0.148 * * *$ & $-0.150 * * *$ \\
\hline & $(-5.80)$ & $(-5.89)$ \\
\hline \multirow[t]{2}{*}{ Market } & $-0.154 *$ & $-0.216 * * *$ \\
\hline & $(-1.87)$ & $(-2.77)$ \\
\hline \multirow[t]{2}{*}{ Indpos } & $-6.496 * * *$ & $-6.602 * * *$ \\
\hline & $(-4.12)$ & $(-4.10)$ \\
\hline \multirow[t]{2}{*}{ _Cons } & $32.500 * * *$ & $32.518 * * *$ \\
\hline & (16.67) & $(16.59)$ \\
\hline Year & Yes & Yes \\
\hline Industry & Yes & Yes \\
\hline $\mathrm{N}$ & 16024 & 16024 \\
\hline adj. R2 & 0.125 & 0.126 \\
\hline $\mathrm{F}$ & 7.556 & 7.557 \\
\hline
\end{tabular}

\subsection{Further Analysis}

Based on the results above, this section further examines the mechanisms by which the diversity of dialects affects corporate strategy and examines the economic conse- 
quences of the mismatch between the company's strategy and the local dialect diversity.

\subsubsection{Mechanism Tests}

The influence of the diversity of dialects on corporate strategy is mainly due to the decline of social trust in the region and the increase in the possibility of trade frictions and pressure of the market competition caused by regional dialect diversification, which forces the management to actively explore the market, give up the cost leading strategy and implement diversification strategy. Following this line of reasoning, we posit that social trust and business diversification play as intermediary factors.

In order to study the intermediary effect of social trust, we use the personal level trust data of "China labor-force dynamics survey " conducted by SUN YAT-SEN University. Regression results are present in Table 4. The coefficient of DiaDiv is significantly negative in Column (2), and the coefficient of Trust is significantly negative in Column (3). Compared with Column (1), the coefficient of DiaDiv has decreased, indicating a partial mediating effect of social trust.

Table 4. Dialect diversity, social trust and corporate strategy

\begin{tabular}{|c|c|c|c|}
\hline & $(1)$ & $(2)$ & $(3)$ \\
\hline & Strategy & Trust & Strategy \\
\hline DiaDiv & $2.397^{* * *}$ & $-0.133^{* * *}$ & $2.082^{* * *}$ \\
\hline & $(11.63)$ & $(-17.19)$ & $(9.91)$ \\
\hline Trust & & & $-2.364 * * *$ \\
\hline & & & $(-8.00)$ \\
\hline cons & $35.388^{* * *}$ & $2.944^{* * *}$ & $42.347^{* * *}$ \\
\hline & $(33.23)$ & $(93.31)$ & $(31.00)$ \\
\hline Control & Yes & Yes & Yes \\
\hline Year & Yes & Yes & Yes \\
\hline Industry & Yes & Yes & Yes \\
\hline $\mathrm{N}$ & 11972 & 11972 & 11972 \\
\hline adj. $R^{2}$ & 0.156 & 0.101 & 0.160 \\
\hline $\mathrm{F}$ & 35.200 & 23.484 & 36.294 \\
\hline
\end{tabular}

We also use sales income of a company at the regional level to measure its diversification (HFI Index), calculated as $H F I=1-\sum_{1}^{n} p_{i}^{2}$, where $\mathrm{N}$ is the number of regions the company operates in, and $p_{i}$ is the proportion of income belonging to each region to the total operating income. The regression results are shown in Table 5. Dialect diversity is significantly positively correlated with diversification, with diversification significantly positively correlated with strategy aggressiveness, verifying the aforementioned strategic adjustment path.
Table 5. Dialect diversity, Diversification and corporate strategy

\begin{tabular}{|c|c|c|c|}
\hline & $(1)$ & $(2)$ & $(3)$ \\
\hline & Strategy & HFI & Strategy \\
\hline DiaDiv & $1.618^{* * *}$ & $0.076^{* * *}$ & $1.540^{* * *}$ \\
\hline & $(8.57)$ & $(6.59)$ & $(8.16)$ \\
\hline HFI & & & $1.038^{* * *}$ \\
\hline & & & $(7.64)$ \\
\hline Control & Yes & Yes & Yes \\
\hline Year & Yes & Yes & Yes \\
\hline Industry & Yes & Yes & Yes \\
\hline $\mathrm{N}$ & 14263 & 14263 & 14263 \\
\hline adj. $R^{2}$ & 0.129 & 0.051 & 0.133 \\
\hline $\mathrm{F}$ & 34.082 & 12.808 & 34.512 \\
\hline
\end{tabular}

\subsubsection{Economic Consequence of Strategic Mis- match}

In order to explore the relationship between the strategic mismatch and the business performance of the enterprise, we use the absolute residual error obtained from the main regression as the explanatory variable and the average return on total asset (ROA) in the next five years as dependent variable to get Table 6. $\left(R O A_{\mathrm{t}+1 \sim t+5}=\alpha_{0}+\alpha_{1}\left|\varepsilon_{i t}\right|+\mu\right)$. The residual that represents the strategic mismatch is significantly negative, indicating that not adapting to the company's locale will indeed negatively affect the company's long-term performance. The main implication is that managers should get more insight into linguistic environment of the enterprise and adjust the strategy prudently.

Table 6. Economic Consequence of Strategic Mismatch

\begin{tabular}{|c|c|c|}
\hline & $(1)$ & $(2)$ \\
\hline ROA & DiaDiv & DiaNum \\
\hline Mismatch & $-0.035^{* *}$ & $-0.034^{* *}$ \\
\hline & $(-2.21)$ & $(-2.11)$ \\
\hline Control & Yes & Yes \\
\hline N & 8280 & 8280 \\
\hline adj. R2 & 0.188 & 0.188 \\
\hline F & 177.960 & 177.931 \\
\hline
\end{tabular}

\subsubsection{Category Discussion}

China 's state-owned enterprises burden "political missions" to support regional employment, so they are more diverse and inclusive when setting and planning strategy than private enterprises. Moreover, state-owned enterprises are much less dependent on external resources and external institutions than private companies, so the impact of dialect diversity on their business expansion will also 
weaken. Therefore, compared with private enterprises, the influence of dialect diversity on state-owned enterprises' strategy might be weakened. In order to testify such assumption, we divide the sample into state-owned and private groups to regress separately. In state-owned group, the coefficient of DiaNum and DiaDiv appears unrelated to strategy. But in private enterprises, the estimated coefficients are all significantly positive and larger in absolute value, passing the Chi2 test, indicating that the influence of dialect diversity on corporate strategy mainly exists in private enterprises but is relatively limited on state-owned enterprises.

Table 7. Dialect diversity, Controlling Shareholder's Nature and corporate strategy

\begin{tabular}{|c|c|c|c|c|}
\hline Score & \multicolumn{2}{|c|}{ Private Enterprises } & \multicolumn{2}{c|}{ State-owned Enterprises } \\
\hline & $(1)$ & $(2)$ & $(3)$ & $(4)$ \\
\hline DiaDiv & $2.484^{* * *}$ & & 0.756 & \\
\hline & $(4.54)$ & & $(1.10)$ & \\
\hline DiaNum & & $0.866^{* * *}$ & & 0.021 \\
\hline & & $(5.89)$ & & $(0.12)$ \\
\hline ControlVars & Yes & Yes & Yes & Yes \\
\hline Year & Yes & Yes & Yes & Yes \\
\hline Industry & Yes & Yes & Yes & Yes \\
\hline N & 10096 & 10096 & 5928 & 5928 \\
\hline adj. R2 & 0.107 & 0.114 & 0.114 & 0.113 \\
\hline Chi2 Test & \multicolumn{2}{|c|}{$22.39 * * *$} & \multicolumn{2}{|c|}{$78.73^{* * *}$} \\
\hline
\end{tabular}

Notes: Robust t-statistics in parentheses; ${ }^{* * *} \mathrm{p}<0.01,{ }^{* *} \mathrm{p}<0.05,{ }^{*} \mathrm{p}<0.1$

Furthermore, the impact of dialect diversity is likely to work only within a certain geographical range, and varies with the size of the enterprise. First of all, when the scale of an enterprise continues to expand, the institutionalization of the enterprise will gradually improve. The balance between strategic choice and environmental adaptation is more due to changes in the relationship of interests brought about by strategic changes. Secondly, with the expansion of the organization scale, the implementation of the strategy will become more difficult, and the ability of the language environment to directly influence the corporate strategy will be weaker. In addition, the larger the scale of an enterprise, the more likely it is that the area covered by its operations will exceed the scope of its registration and be distributed nationwide. Then the link between the diversity of dialects in a single region and the corporate strategic development considerations will be weaker. Therefore, we establish a hypothesis that the influence of dialect diversity on corporate strategy becomes weaker as the enterprise scales larger. We include the interaction term Size $\times$ DiaDiv and Table 8 reports the results. The coefficients of the interaction term are significantly negative, in support of our conjecture, providing reassuring evidence that the bigger scale will indeed weaken the influence of dialect culture on corporate strategy.

Table 8. Dialect diversity, corporate scale and corporate strategy

\begin{tabular}{|c|c|c|}
\hline \multirow{2}{*}{ DiaDiv } & $\begin{array}{c}(1) \\
\text { DiaDiv }\end{array}$ & $\begin{array}{c}(2) \\
\text { DiaNum }\end{array}$ \\
\hline \multirow{2}{*}{ Size×DiaDiv } & $1.880^{* * *}$ & \\
\cline { 2 - 3 } & $(4.09)$ & \\
\cline { 2 - 3 } & $-0.024^{* *}$ & \\
\hline \multirow{2}{*}{ DiaNum } & $(-2.23)$ & \\
\cline { 2 - 3 } & & $0.555^{* * *}$ \\
\hline \multirow{2}{*}{ size×DiaNum } & & $(4.64)$ \\
\hline ControlVars & & $-0.004^{* * *}$ \\
\hline Year & Yes & $(-2.82)$ \\
\hline Industry & Yes & Yes \\
\hline $\mathrm{N}$ & 16024 & Yes \\
\hline adj. R2 & 0.127 & 0.128 \\
\hline F & 8.564 & 8.630 \\
\hline
\end{tabular}

Notes: Robust t-statistics in parentheses; *** $\mathrm{p}<0.01, * * \mathrm{p}<0.05, * \mathrm{p}<0.1$

Still further, we divide sample into four groups according to ownership structure (whether CEO is also board chairman) and CEO's familiarity with the regional culture (whether CEO's native place or birthplace is identical to company's register city) to study the moderator effect of managerial features in the relationship between dialect diversity and company's strategy. As shown in Table 9, the coefficient of DiaNum and the adjusted R-square increase with the improvement of the manager's board status and the manager's familiarity of the local culture.

Table 9. Dialect diversity, governance features and corporate strategy

\begin{tabular}{|c|c|c|c|c|}
\hline \multirow{4}{*}{ Strategy } & $\begin{array}{c}\text { Two-Post Ar- } \\
\text { rangement }\end{array}$ & $\begin{array}{c}\text { Two-Post Ar- } \\
\text { rangement }\end{array}$ & $\begin{array}{c}\text { CEO } \\
\text { duality }\end{array}$ & $\begin{array}{c}\text { CEO } \\
\text { duality }\end{array}$ \\
\cline { 2 - 5 } & Outland CEO & Local CEO & $\begin{array}{c}\text { Outland } \\
\text { CEO }\end{array}$ & $\begin{array}{c}\text { Local } \\
\text { CEO }\end{array}$ \\
\hline DiaNum & $0.226^{*}$ & $0.583 * * *$ & $0.861 * * *$ & $1.021^{* * *}$ \\
\hline $\begin{array}{c}\text { Control- } \\
\text { Vars }\end{array}$ & $(1.66)$ & $(2.86)$ & $(2.65)$ & $(2.99)$ \\
\hline Year & Yes & Yes & Yes & Yes \\
\hline Industry & Yes & Yes & Yes & Yes \\
\hline $\mathrm{N}$ & 1877 & 1122 & Yes & Yes \\
\hline adj. $R^{2}$ & 0.185 & 0.253 & 0.271 & 0.294 \\
\hline
\end{tabular}




\subsection{Robustness Test}

In order to ensure the reliability of the main conclusion, we have conducted robustness tests from the following aspects:

\subsubsection{Instrumental Variable Regression}

In order to overcome possible endogenous problems, we use Chinese terrain gradient index extracted by Feng Zhiming et al. (2007) as a tool variable to re-examine the impact of cultural diversity on the degree of corporate strategy aggressiveness. The formation of culture is usually closely related to the terrain. Generally speaking, the more complicated the terrain and the greater the slope, the more likely this area is divided into different relatively closed small areas in its history, so that the area forms multiple dialects, that is, the dialect diversity of a region is positively related to its terrain slope. However, corporate strategy will not affect the natural condition of terrain, especially in modern society. It can be safely considered that the terrain slope has no direct impact on the corporate strategy.

Table 10 gives the estimated results of 2SLS. Columns (1)-(2) are the regression results of first stage. Slope is significantly positively correlated with the two dialect diversity indicators, indicating that the terrain slope can be used as an instrumental variable for dialect diversity. The F statistic of the weak instrument variable test is 13.495 and 194.168 respectively, both of which rejects the existence of the weak instrument variable. Columns (3)-(4) are the second stage regression results. The coefficients on dialect are still statistically significantly positive. Our conclusion is further strengthened by the evidence.

Table 10. Regression results of instrumental variables

\begin{tabular}{|c|c|c|c|c|}
\hline \multirow{2}{*}{ Variables } & $(1)$ & $(2)$ & $(3)$ & $(4)$ \\
\cline { 2 - 5 } & DiaDiv & DiaNum & Score & Score \\
\hline DiaDiv & & & $36.639 * * *$ & \\
\hline DiaNum & & & $(3.09)$ & \\
\hline & & & & $2.536 * * *$ \\
\hline Slope & $0.011 * * *$ & $0.156 * * *$ & & $(5.48)$ \\
\hline & $(3.67)$ & $(13.93)$ & & \\
\hline ControlVars & Yes & Yes & Yes & Yes \\
\hline Year & Yes & Yes & Yes & Yes \\
\hline Industry & Yes & Yes & Yes & Yes \\
\hline N & 16024 & 16024 & 16024 & 16024 \\
\hline adj. R2 & 0.1073 & 0.1137 & 0.1142 & 0.1132 \\
\hline
\end{tabular}
consistent after all above refined tests.

\section{Conclusion} measures, and matched samples. plagued by uncaptured factors, we first alternate measurement of strategy by using two dummy variables, where PROS is coded one if strategy score is above 24 and DEFE is coded one if strategy score is below 12 . We then include the per capita gross domestic product (PerGDP) and regional gross domestic product (GDP) in a city for the controls of regional economic development. And to exclude the influence of population flow, we remove the sample in Beijing, Shanghai, Guangzhou, Shenzhen and rerun the regression test. Our conclusions remain highly

In a corporate decision-making process that fully considers the matching of strategy with the external environment, regional culture has an impact on the interactive behavior of corporate organizations, and largely determines the development ideas and strategies of the enterprise. Dialect diversity, as an important part of an enterprise's language environment, has a subtle influence on the enterprise's enthusiasm for R\&D, resource acquisition, transaction cost, asset composition, personnel structure, and capital flow, which has significance for the strategy of the enterprise. This paper conducts an empirical analysis to examine the effect of dialect diversity in the enterprise's location on the corporate strategic aggressiveness. We argue that higher dialect diversity in an enterprise's location leads the corporate strategy to be more aggressive and misfit of strategy has negative effect on long-term performance; Moreover, the increase in strategy aggressiveness is due partly to the weakening of social trust as well as an increase of business diversification tendency. To further characterize this effect, we explore that the influence of dialect diversity on strategy is more pronounced as managers' awareness of the dialectal environment increases, but is weaken if the enterprise is a state-owned enterprise or has larger scale. Our results are robust to various controls, alternative

The research in this paper enriches literatures on strategy management and shed light on managing practice, highlighting the importance of understanding the crucial link between the cultural environment and the setting of corporate strategy, which is, firms need to align their strategy to their "dialect condition" and other seemingly irrelevant factors because the fit between strategy and the culture will affect performance positively. 


\section{References}

[1] Ahern K. R., Daminelli D., Fracassi C., 2015, “Lost in translation? The effect of cultural values on mergers around the world", Journal of Financial Economics, 117(1), pp.165 189.

[2] Bentley K. A., Omer T. C., Sharp N. Y., 2013, "Business Strategy, Financial Reporting Irregularities, and Audit Effort”, Contemporary Accounting Research, 30(2), pp.780 817.

[3] Chen Z., Lu M., Xu L., 2014, "Returns to dialect", China Economic Review, 30, pp.27 43.

[4] Guiso L., Sapienza P., Zingales L., 2009, “Cultural Biases in Economic Exchange?", Quarterly Journal of Economics, 124(3), pp.1095 1131.

[5] Hegde D. \& Tumlinson J., 2014, "Does Social Proximity Enhance Business Partnerships? Theory and Evidence from Ethnicity's Role in U.S. Venture Cap- ital”, Management Science, 60(9), pp.2355 2380.

[6] Melitz J. \& Toubal F., 2014, "Native language, spoken language, translation and trade", Journal of International Economics, 93(2), pp.351 363.

[7] Miles R. E., Snow C. C., Meyer A. D., Coleman H. J., 1978, "Organizational strategy, structure, and process", Acad Manage Rev, 3(3), pp.546 562.

[8] Volonté C., 2015, "Culture and Corporate Governance: The Influence of Language and Religion in Switzerland", Management International Review, 55(1), pp.77 118.

[9] Xu Xianxiang, Liu Yuyun, Xiao Zekai: Dialects and Economic Growth[J]. Journal of Economics, No. 02, 2015.

[10] Feng Zhiming, Tang Yan, Yang Yanzhao: “Topographic fluctuations in China and its correlation with population distribution" [J]. Journal of Geography, 2007, Issue 10. 